\title{
Thermodynamic Analysis for Hybrid Low Temperature Sustainable Energy Sources in Cascade Heat Pump Technology
}

\author{
Ali H. Tarrad \\ Mechatronic Department \\ University of Southern Denmark, Denmark \\ Email:alitarrad [AT] mci.sdu.dk
}

\begin{abstract}
A thermodynamic analysis of compound Cascade refrigeration system at low temperature heat sources was conducted. The analysis was based on a target temperature of hot water at the range of $(60-70){ }^{\circ} \mathrm{C}$ out of the heat pump. The carrier thermal fluid temperature, which provides heat at the low temperature side of the Cascade system, determines the pair of refrigerants to be implemented. A hybrid heat pump design was proposed, which implements the sea water and ground as heat sources in a compound cycle. Two of refrigerant pairs were tested for the performance and energy efficiency comparison at fixed operating conditions. In the low temperature cycle, either R410A or R717 refrigerant was allowed to circulate and R134a is circulated at the high temperature cycle. The minimum isentropic efficiency of commercially available compressors was used in this investigation, a value of (70 \%) was chosen. The results of the investigation revealed that R717/R134a exhibited a higher heating (COP) than that of R410A/R134a by (3\%). The results showed that increasing the isentropic efficiency of compressors to (90\%) improved the heating (COP) by (20\%) and minimized the power consumption by (24\%). The specific power consumed by compressors of the proposed system showed a decrease of upto (3\%) lower than that of the sea water base system.
\end{abstract}

Keywords---- Cascade System, Green Environment, Refrigerant Alternatives, Low Temperature, Clean Heat Source

\section{INTRODUCTION}

Cascade system arrangement is widely selected for heat pumps when the temperature lift of the system is quite high. This represents the temperature difference between the high temperature cycle condenser and low temperature cycle evaporator of the cascade system. Therefore, two cycles are working independently and connected through the use of a cascade heat exchanger. In this heat exchanger, the refrigerant vapor of the low side is condensed and the liquid of the high side is evaporated. Similar or different refrigerants can be circulated separately for each cycle.

The choice of refrigerants on both sides of the Cascade system is quite a difficult task. It depends on the temperature of the heat source, physical properties of refrigerants and performance factors of the machine. It also depends on the refrigerant Ozone Depletion Potential (ODP), Global Warming Potentials (GWP), toxicity and flammability.

Enormous number of investigations has been carried out with a variety of refrigerant pairs in Cascade systems. Lee et al. (2005) [1] implemented Carbon dioxide and ammonia (R744/ R717) to the cascade system and theoretically analyzed the optimal condensation temperature of R744 in the low temperature cycle of the cascade system. Bhattacharyya et al. (2006) [2] preferred to use Carbon dioxide and propane (R744/R290) over ammonia, which is a natural but toxic and inflammable refrigerant in a cascade system. Their investigation was focused on the performance and to determine the optimal evaporation temperature of $\mathrm{CO} 2$ in a high-temperature cycle suitable for heating. Bingming et al. (2009) [3] and Dopazo and FernándezSeara (2011) [4] provided experimental optimum intermediate temperature in the $\mathrm{NH} 3 / \mathrm{CO} 2$ cascade heat pump system. They concluded that optimized intermediate temperature should be obtained at a fixed heating capacity. Kim et al. (2012) [5] studied experimentally the performance of air to water heat pump, which circulates R134a and R410A as refrigerants on the high and low cycle respectively. They concluded that the performances are deteriorated at high water inlet temperature and low ambient temperature. The optimal intermediate temperature is increased as ambient temperature increases and water inlet temperature increases.

Experimental investigation was conducted on $\mathrm{R} 134 \mathrm{a} / \mathrm{R} 410 \mathrm{~A}$ cascade cycle for variable refrigerant flow heat pump systems by Kim et al. (2015) [6]. (COP) increased up to $16 \%$ when water inlet temperature decreased. Their experiments revealed that when the ambient temperature was $7^{\circ} \mathrm{C}$, the higher $(C O P)$ condition was realized when the intermediate temperature was $(40-41){ }^{\circ} \mathrm{C}$, regardless of the water inlet temperature to the high temperature condenser. Minglu et al. (2016) 
[7] proposed a control strategy for Cascade air source heat pump water heater to adjust the load variation. They concluded that controller developed successfully helped realize the control of the intermediate pressure, the degree of superheat and the evaporating temperature in terms of control accuracy and sensitivity.

The underground temperature approaches a constant value of (17) ${ }^{\circ} \mathrm{C}$ year round at a depth of (5) $\mathrm{m}$. In the cooling season, the geothermal heat pump extracts heat from the space to be cooled and rejects it to the ground through a heat exchanger. In winter, the geothermal heat pump takes natural heat from the ground and transfers it to the home or building for heating. The geothermal concept may also be implemented for district water heating demands by the community. A geothermal heat pump system can be the most cost-effective and efficient thermal performance for home heating and cooling option. It has been found that the geothermal heat pump systems experience an average 20+ year life expectancy for the heat pump itself and (25 to 50) years for the underground infrastructure. Additionally, the coefficient of performance of this type of heat pumps is ranged between (3) and (5) depending on the operating conditions, (2011) [8]. The ground heat exchanger is buried either horizontally in a shallow trench at a depth of (1-2) m or vertically in a borehole. In general, the cost of trenching and drilling of boreholes are higher than the cost of heat exchanger and piping. Therefore, it is important to maximize the heat extraction or rejection per unit length of trench/borehole.

Ozgener and Hepbasli (2007) [9] stated that the energy performance of a ground source heat pump (GSHP) is influenced by the heat pump machine, the circulating pump or well pumps, and the ground coupling or ground water characteristics. Yrjölä and Laaksonen (2015) [10] investigated a ground source heat pump system when circulating R407C and R134a on the (LT) and (HT) cycles respectively. They found that when the evaporating temperature of R407C and condensing temperature of R134a are constants at $(-5){ }^{\circ} \mathrm{C}$ and $(65){ }^{\circ} \mathrm{C}$ respectively, then the optimum condensing temperature of the (LT) proved to be (35-37) ${ }^{\circ} \mathrm{C}$. Uhlmann et al. (2014) [11] investigated the performance of heat pump with different heat sources such as buildings with a heat pump and a solar thermal collector or buildings with waste heat recovery. They concluded that the proposed cycle can use varying amounts of waste heat and increases the heat pump efficiency by up to $30 \%$ over a wide range of operating conditions.

There are three generations of hot water supply to match the community demands, Lund et al. (2014) [12]. In the $1^{\text {st }}$ generation, steam was used as a heat carrier. Steam temperature produce substantial losses, accident from steam explosion, and less efficiency. The $2^{\text {nd }}$ and $3^{\text {rd }}$ generations use a pressurized hot water as heat carriers and the supply temperature at over (100) ${ }^{\circ} \mathrm{C}$ and below (100) ${ }^{\circ} \mathrm{C}$ respectively. The motivation for these generations is to minimize the installation cost, maintenance cost and operating risks. The $4^{\text {th }}$ generation which the scientists are working on at the present time is the development of technology to supply of hot water as a heat carrier at a temperature range of $(40-50){ }^{\circ} \mathrm{C}$. The main purpose of this generation is to utilize all of the available clean heat sources, zero (CO2) emission, low temperature supply to the District heating system technology and more flexible materials.

In the present study; the concept of multi-heat sources at low temperature will be addressed. It is suggested to use both of heat sources, the sea water and underground as a heat supply sources in a modified Cascade compound system. The sea water heat source is to be implemented at the low temperature side and the ground source for the intermediate pressure evaporator or superheater heat exchanger. This multi-evaporator and individual expansion valves with two compressors cycle is integrated as a part of the Cascade system at the (LT) cycle with two different refrigerants.

\section{METHODOLOGY AND CASE STUDY}

The harness of sustainable and environmental friendly heat sources has been considered for many decades. It took a great consideration in the research and application with enormous effort to implement this concept in the domestic and industrial fields. It has been used for air conditioning and hot water production for household, hotels, industrial buildings and public usage demands. District heating is designed of a network of piping system connecting buildings in a neighborhood, town centre or whole city, in a way that they can be supplied by a hot water from centralized plants. The operating conditions of the heating mediums for both of the heat sources are shown in table (1) for the proposed system. 
Table 1: Operating conditions of the low temperature cycle for the cascade system

\begin{tabular}{|c|c|c|c|c|c|}
\hline Heat Source & $\begin{array}{c}\text { Evaporator } \\
\left({ }^{\circ} \mathbf{C}\right)\end{array}$ & $\begin{array}{c}\text { Heating Medium } \\
\text { (Brine) }\end{array}$ & $\begin{array}{c}\text { Inlet } \\
\left({ }^{\circ} \mathrm{C}\right)\end{array}$ & $\begin{array}{c}\text { Exit } \\
\left({ }^{\circ} \mathrm{C}\right)\end{array}$ & $\begin{array}{c}\text { Freezing Point } \\
\left({ }^{\circ} \mathrm{C}\right)\end{array}$ \\
\hline Sea Water & -10 & $\begin{array}{c}30 \% \text { Ethylene } \\
\text { Glycol/Water }\end{array}$ & 5 & -4 & -14 \\
\hline Ground & -5 & $\begin{array}{c}\text { 20\% Propylene } \\
\text { Glycol/Water }\end{array}$ & 5 & -2 & -8 \\
\hline
\end{tabular}

\subsection{Heat Source Characteristics}

It is suggested to use heat carrier mediums at supply temperature for both evaporators at $(5){ }^{\circ} \mathrm{C}$ which could be attained easily by the thermal fluids. The sea water temperature depends on the depth from which water is extracted, for depth range between (11-20) $\mathrm{m}$; the temperature reaches an attractive range as (7-10) ${ }^{\circ} \mathrm{C}$. The underground heat source also depends on the depth at which the piping collector is buried, the ground temperature reaches a constant value at a depth below (5) $\mathrm{m}$ depth year round. Although it depends on location, ground composition and climate conditions, it still varies between (10-20) ${ }^{\circ} \mathrm{C}$ at depth around (2) $\mathrm{m}$ year round. Hence, a supply temperature of a heating medium at a value of $(5){ }^{\circ} \mathrm{C}$ is a practical value to be considered for this study.

The heating medium characteristic selection depends on a general rule for its freezing point. It should be at least (5) ${ }^{\circ} \mathrm{C}$ lower than the estimated mean operating temperature of the heating medium as it passes through the heat exchanger (evaporator), (2007) [13]. Accordingly, the glycol/water brines for both heating heat sources were chosen as shown in table (1). Two refrigerant systems are studied which implement the sea water and ground heat sources in hybrid arrangements as a part of a compound Cascade unit on the low temperature cycle.

\subsection{Power Consumption}

The power consumed by the proposed system depends mainly on the efficiency of the available compressor and technology. Most of the companies of commercially available compressors state that the isentropic efficiency of their products is laid in the range of $(70 \%)$ to $(90 \%)$. The selection of isentropic efficiency is of a vital importance in the thermal performance assessment of the proposed compound Cascade system (COP) and hence its thermal efficiency. Therefore, it was decided to use the minimum published isentropic efficiency of commercial compressors. Any increase in this factor will of course enhance the $(C O P)$ of the system considerably.

\subsection{Multi-Evaporators Compound Cycle}

This Cascade system consisted of multi-evaporators, individual expansion valves and multi-compressors as shown in figure (1). The low temperature cycle comprises two evaporators, the low temperature evaporator is provided with heat from the sea water source and the intermediate temperature evaporator uses the ground heat source. 


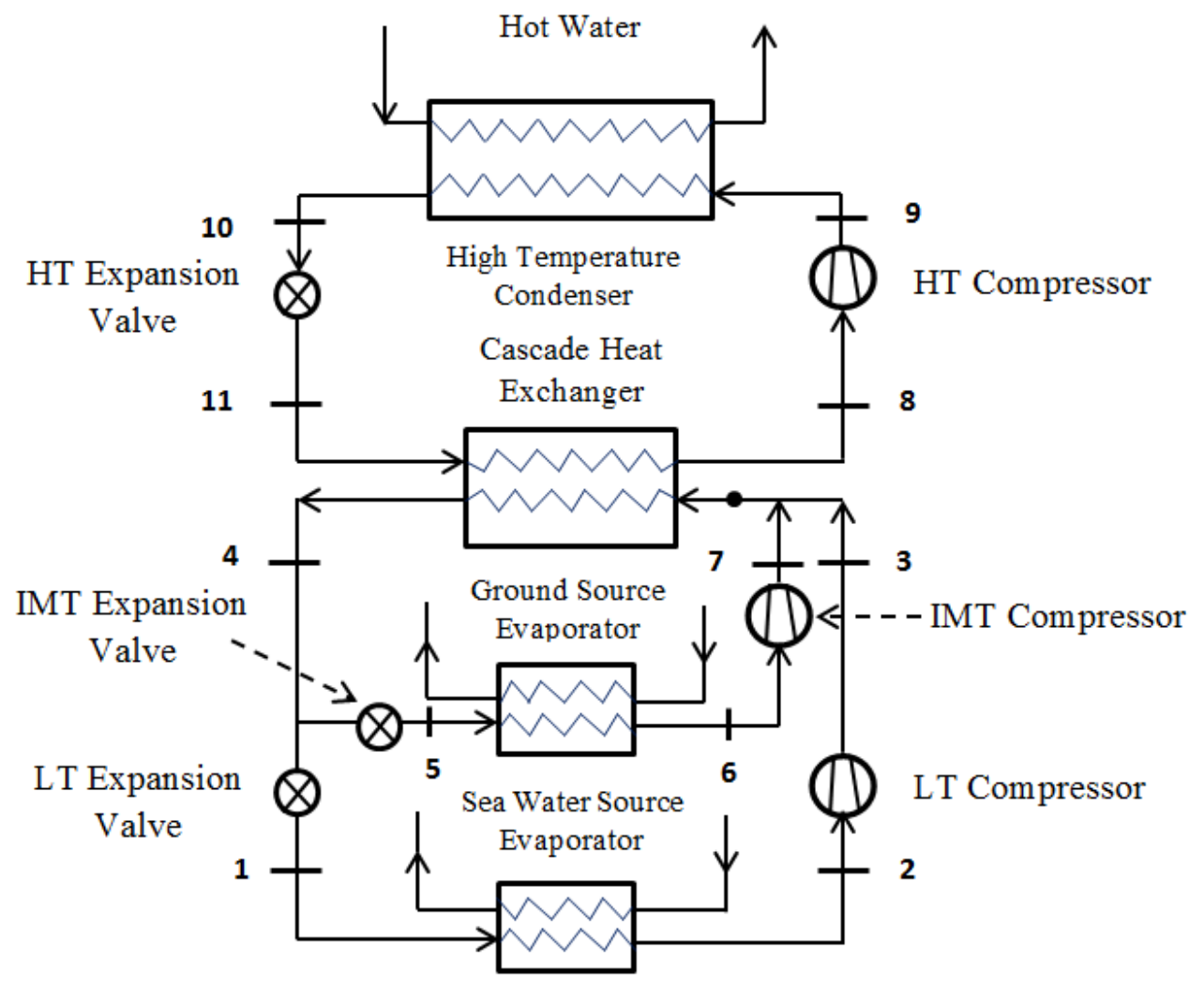

Figure (1): A schematic diagram for the proposed Cascade system

The compressors of both cycles discharge the refrigerant gases at the same pressure with different temperatures. The energy and mass balances in the mixing line determines the condition of the gas enters the cascade heat exchanger for condensation process; it is designated as solid circle, point $(\mathrm{m})$ on the diagram. The high temperature cycle composes from the principle components of a compression refrigeration cycle and the output of the heat pump is the hot water discharged out of the condenser in this cycle. The p-h diagram of this cycle is illustrated in figure (2). In both evaporators discharge ports, it is assumed that gases leave as superheated condition to $(0){ }^{\circ} \mathrm{C}$ at the operating pressure. The gas could be superheated to a higher value with the suggested heating mediums and heat sources, but for comparison it was fixed at $(0){ }^{\circ} \mathrm{C}$. 


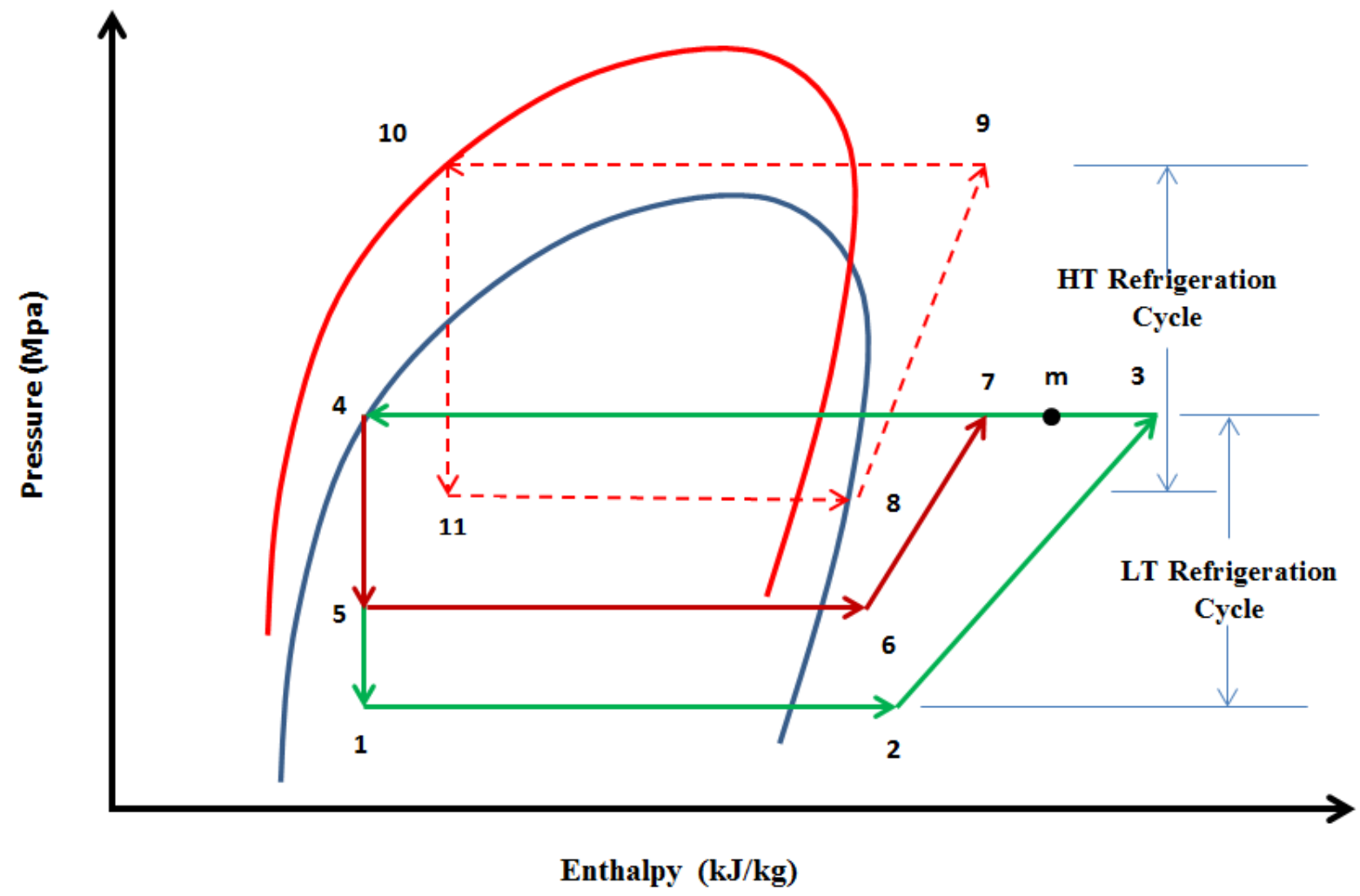

Figure 2: A schematic p-h diagram for the compound Cascade system

The temperature distribution of both streams at the low temperature and the intermediate temperature evaporators is presented in figure (3). The ethylene glycol/water solution is used as a heat source medium for the sea water source evaporator, the low temperature one, figure (3.a). Whereas, the intermediate temperature evaporator which uses propylene glycol water brine as a heat medium for the ground source is shown in figure (3.b).

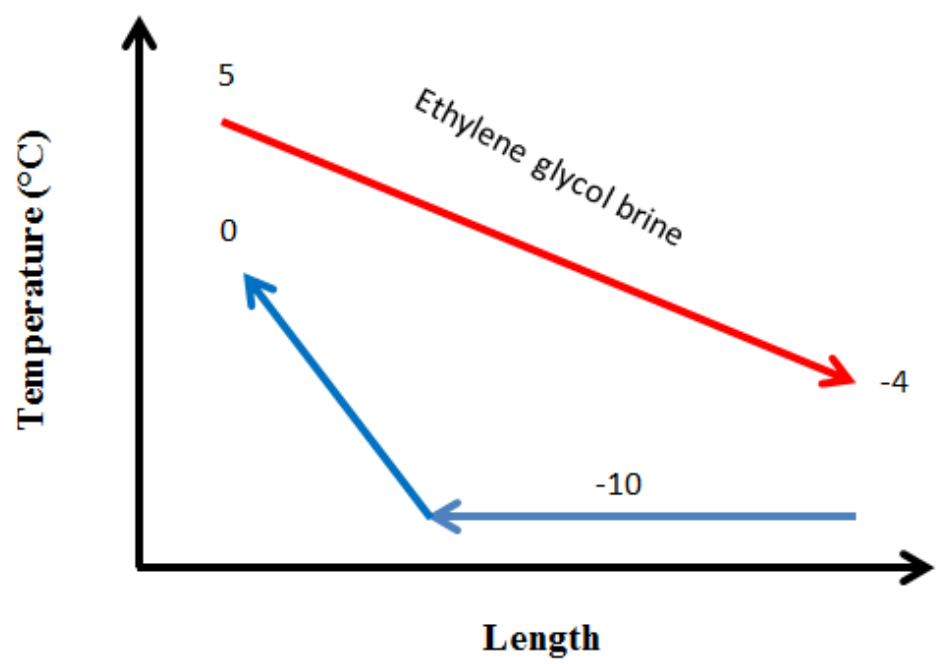

Figure 3.a: Ethylene glycol solution/low temperature cycle at low temperature evaporator for sea water source 


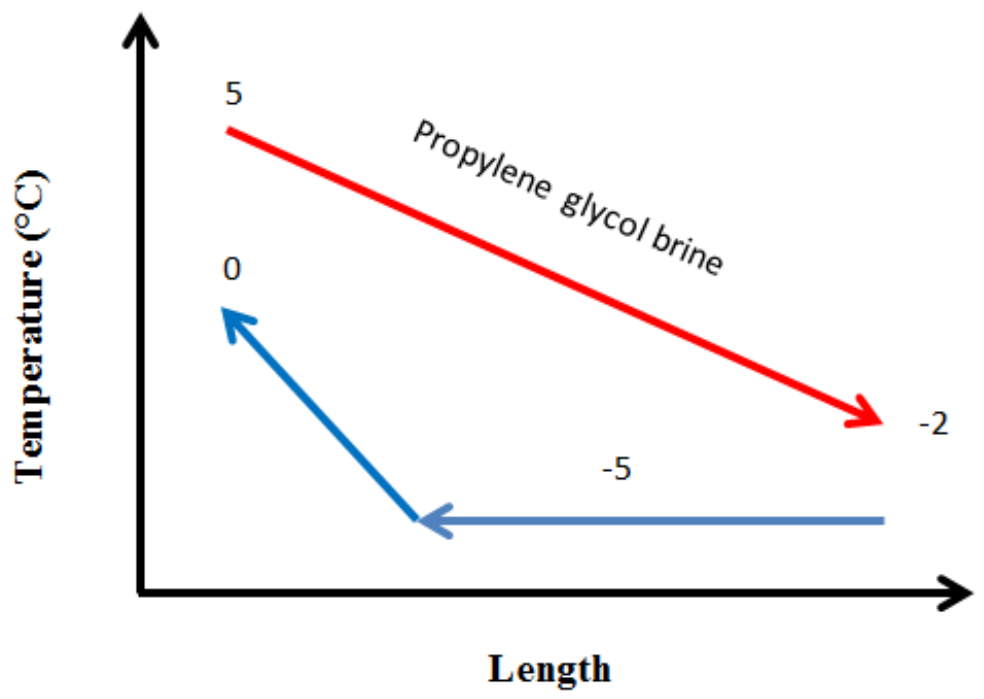

Figure (3.b): Propylene glycol solution/low temperature cycle at intermediate evaporator for ground source

\section{THERMODYNAMIC ANALYSIS}

The basic thermodynamic relations are applied to each component of the Cascade heat pump system shown in figure (1). The notations used in figure (2) can be implemented for the thermal analysis with the aid of the known input heat load of each cycle.

\subsection{Low Temperature Cycle}

The sea water heat source provides heat load to the (LT) evaporator, stream path (1-2) in figure (2), (30\%) ethylene glycol/water mixtures enters at a temperature of $(5){ }^{\circ} \mathrm{C}$. The temperature variation through the evaporator is represented by figure (3.a). The mass flow rate of refrigerant is estimated from the heating load, energy balance and adiabatic boundary condition as:

$$
\dot{m}_{L T}=\frac{\dot{Q}_{L T, e v a p}}{\left(h_{2}-h_{1}\right)}
$$

Similarly, the intermediate temperature (IMT) evaporator is supplied with heat from the ground heat source, $(20 \%)$ propylene glycol/water solution at a temperature of (5) ${ }^{\circ} \mathrm{C}$. Figure (3.b) shows the temperature variation to provide superheat of (5) ${ }^{\circ} \mathrm{C}$ on the refrigerant side. The evaporator is located between points (5) and (6) in figures (1) and (2). The mass flow rate of refrigerants that is circulated through this cycle is estimated from:

$$
\dot{m}_{I M T}=\frac{\dot{Q}_{I M T, e v a p}}{\left(h_{6}-h_{5}\right)}
$$

The discharge gas from both of the (LT) and (IMT) compressors at the low temperature cycle are mixed before entering the cascade heat exchanger at thermodynamic condition designated as point $(\mathrm{m})$. Its enthalpy can be estimated from the energy balance as:

$$
h_{m}=\frac{\dot{m}_{L T} \times h_{3}+\dot{m}_{I M T} \times h_{7}}{\left(\dot{m}_{L T}+\dot{m}_{I M T}\right)}
$$

This heat exchanger works as an evaporator for the high temperature (HT) cycle between (11) and (8) stream points for refrigerant R134a. The condensation load of this heat exchanger is estimated as:

$$
\dot{Q}_{\text {cascade }}=\left(\dot{m}_{L T}+\dot{m}_{I M T}\right) \times\left(h_{m}-h_{4}\right)
$$

The power consumption by (LT) and (IMT) compressors may be calculated from:

$$
\dot{W}_{L T}=\dot{m}_{L T}\left(h_{3}-h_{2}\right)
$$


And

$$
\dot{W}_{I M T}=\dot{m}_{I M T}\left(h_{7}-h_{6}\right)
$$

\subsection{High Temperature Cycle}

The refrigerant path of this cycle flows through the cycle (8-9-10 and 11) in figures (1) and (2). The evaporator is represented by the path bounded by points (11) and (8) which extracts heat from the condensation of the (LT) cycle refrigerant in the cascade heat exchanger. The mass flow rate of the refrigerant is estimated from the energy balance through the cascade heat exchanger to give:

$$
\dot{m}_{H T}=\frac{\dot{Q}_{\text {cascade }}}{\left(h_{8}-h_{11}\right)}
$$

The power consumption of the (HT) compressor is expressed as:

$$
\dot{W}_{H T}=\dot{m}_{H T}\left(h_{9}-h_{8}\right)
$$

The heating load output of the heat pump represents the condensation load at the (HT) condenser located between points (9) and (10) in figures (1) and (2) is calculated from:

$$
\dot{Q}_{H T, \text { cond }}=\dot{m}_{H T}\left(h_{10}-h_{9}\right)
$$

\subsection{Coefficient of Performance (COP)}

It represents the ability of the heat pump to move heat from the low temperature source to a higher level with a lower power input. The higher the value of heat output for a given power input the better thermal performance and economic feasibility will be attained. It is defined as:

$$
\mathrm{COP}_{\text {System }}=\frac{\dot{Q}_{H T, \text { cond }}}{\dot{W}_{\text {total,comp }}}
$$

Where the total power consumption of the cascade system on the refrigerant side is calculated by:

$$
\dot{W}_{\text {total,comp }}=\dot{W}_{L T}+\dot{W}_{I M T}+\dot{W}_{H T}
$$

\section{RESULTS AND DISCUSSION}

The Cascade system will be examined with two of selected refrigerant pairs listed in table (2) for performance comparison. The following conditions are to be considered:

- Cascade system with superheated degree of $(10){ }^{\circ} \mathrm{C}$ for (LT) and $5{ }^{\circ} \mathrm{C}$ for intermediate and (HT) evaporators. There is no subcooling in condensers at both of the (LT) and (HT) cycles.

- The (HT) evaporation and condensation are at $(26 \text { and } 30)^{\circ} \mathrm{C}$ and $(75){ }^{\circ} \mathrm{C}$ respectively with (LT) condenser at $(40){ }^{\circ} \mathrm{C}$.

- The compressors are operating at (70\%) and (80\%) isentropic and volumetric efficiencies respectively with $(10 \%)$ heat loss.

- Heat load input of (2.1) $\mathrm{kW}$ from the sustainable sources at different contribution percentage. This value produces approximately (3.5) $\mathrm{kW}$ as heating output of the Cascade system at compressors isentropic efficiency of (70 \%).

- Neglecting any additional superheat and subcooling that can be obtained from the piping system at the suction side of compressors and discharge piping after condensers.

The contribution of the ground heat source to the total heat input is represented by:

$$
\alpha=\frac{\dot{Q}_{G-S}}{\dot{Q}_{L T C, \text { evap }}}
$$


Table 2.a: Operating conditions of both sides of the Cascade system

\begin{tabular}{|c|c|c|c|c|}
\hline \multirow{2}{*}{$\begin{array}{c}\text { Temperature } \\
\left({ }^{\circ} \mathbf{C}\right)\end{array}$} & \multicolumn{2}{|c|}{ Pressure (bar) } & \multirow{2}{*}{$\begin{array}{c}\text { R134a Temperature } \\
\left({ }^{\circ} \mathbf{C}\right)\end{array}$} & \multirow[t]{2}{*}{ Pressure (bar) } \\
\hline & R410A & R717 & & \\
\hline-10 & 5.759 & 2.908 & 26 & 6.853 \\
\hline-5 & 6.803 & 3.548 & 30 & 7.701 \\
\hline 40 & 23.981 & 15.549 & 75 & 23.634 \\
\hline \multirow[t]{2}{*}{ Expansion Valve Designation } & \multicolumn{2}{|c|}{$\begin{array}{c}\text { LT Cycle Pressure Ratio } \\
@ 40^{\circ} \mathrm{C} \text { Condensation }\end{array}$} & \multicolumn{2}{|c|}{$\begin{array}{c}\text { HT Cycle Pressure Ratio } \\
\text { R134a }\end{array}$} \\
\hline & R410A & $\mathbf{R 7 1 7}$ & Evap. @ 26 ${ }^{\circ} \mathrm{C}$ & Evap. @ 30 ${ }^{\circ} \mathbf{C}$ \\
\hline LT @ -10 ${ }^{\circ} \mathrm{C}$ & 4.164 & 5.347 & \multirow[b]{2}{*}{3.449} & \multirow[b]{2}{*}{3.069} \\
\hline IM @ -5 ${ }^{\circ} \mathrm{C}$ & 3.525 & 4.383 & & \\
\hline
\end{tabular}

Table 2.b: Operating conditions of the Cascade heat exchanger for (HT) cycle condensation temperature of $75^{\circ} \mathrm{C}$

\begin{tabular}{|c|c|c|c|c|c|c|c|}
\hline \multicolumn{3}{|c|}{$\begin{array}{c}\text { Cascade Heat Exchanger } \\
\left({ }^{\circ} \mathbf{C}\right)\end{array}$} & \multicolumn{2}{c|}{$\begin{array}{c}\text { LT Cycle Condenser Pressure (bar) } \\
\text { @ 40 }\end{array}$} & \multicolumn{3}{c|}{$\begin{array}{c}\text { HT Cycle Pressure (bar) } \\
\text { R134a Refrigerant }\end{array}$} \\
\hline Evaporator & Condenser & Intermediate & R410A & R717 & Evap. & Cond. & Ratio \\
\hline 30 & 40 & 35 & 23.981 & 15.549 & 7.701 & 23.634 & 3.069 \\
\hline 26 & 40 & 33 & 23.981 & 15.549 & 6.853 & 23.634 & 3.449 \\
\hline
\end{tabular}

Selected physical properties for the studied refrigerant pairs are listed in table (3). These refrigerants were selected according to their thermal and characteristic operating conditions.

Table 3: Some selected physical properties of the suggested refrigerants

\begin{tabular}{|l|c|c|c|}
\hline \multicolumn{1}{|c|}{ Property } & R-410A & R717 & R134a \\
\hline (Formula) & $\begin{array}{c}\text { R32/125 } \\
(50 / 50) \% \text { by } \\
\text { Weight }\end{array}$ & $\begin{array}{c}\text { NH3 } \\
(100) \%\end{array}$ & $\begin{array}{c}\text { CF3CH2F } \\
(100) \%\end{array}$ \\
\hline Molecular Weight $(\mathrm{kg} / \mathrm{kmol})$ & 72.58 & 17.03 & 102.03 \\
\hline Normal Boiling Point $\left({ }^{\circ} \mathrm{C}\right)$ & -51.58 & -33.3 & -26.06 \\
\hline Temperature Glide $\left({ }^{\circ} \mathrm{C}\right)$ & $<0.2$ & 0 & 0 \\
\hline Critical Pressure $(\mathrm{MPa})$ & 4.926 & 11.3 & 4.0603 \\
\hline Critical Temperature $\left({ }^{\circ} \mathrm{C}\right)$ & 72.13 & 132.4 & 101.08 \\
\hline Ozone Depletion Potential & 0 & 0 & 0.005 \\
\hline Global Warming Potential & 1725 & 0 & 1430 \\
\hline
\end{tabular}

\subsection{Heat Load Output}

The base input load was set at $2.1 \mathrm{~kW}$ as a total heat load extracted from the external sources. The Cascade heat pump output was estimated according to the thermodynamic analysis stated above with low temperature cycle modification.

\section{(i) R410A/R134a System}

The general trend of the load variation with $(\alpha)$ showed a higher heat output with a lower intermediate temperature of (33) ${ }^{\circ} \mathrm{C}$ at the cascade heat exchanger for which R134a evaporates at (26) ${ }^{\circ} \mathrm{C}$. This is mainly due to the higher temperature lift on the (HT) cycle which in turn leads to higher power consumption to achieve the compression ratio. In addition, the variation showed a highest value for the load output of the hybrid system at $(\alpha)$ near (15\%) as illustrated in figure (4). 


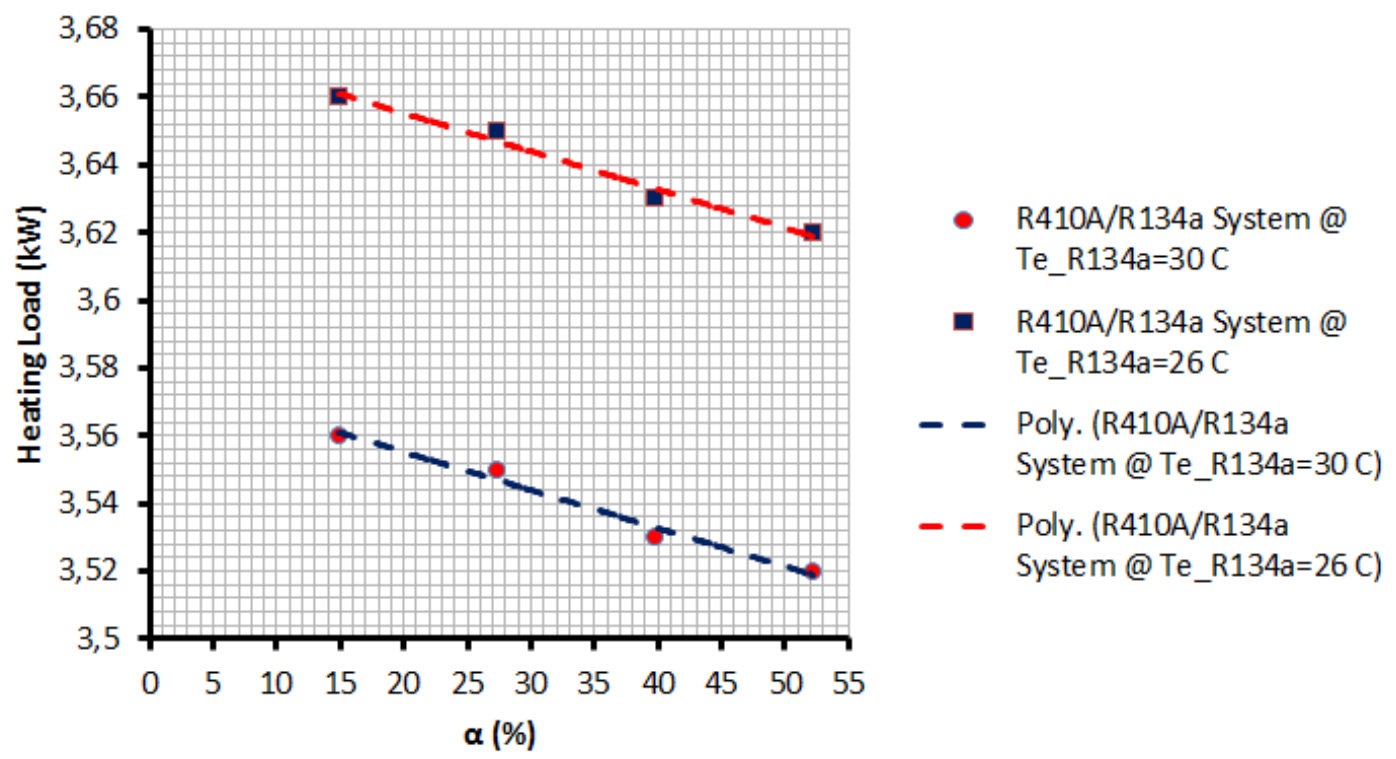

Figure 4: Heat pump heating load variation comparison at different intermediate temperature with $(\alpha)$ parameter for R410A/R134a system

The trend of the results show a declination for the total heating load output with increasing the ground source contribution $(\alpha)$ at the intermediated evaporator temperature. It approaches a minimum value at a point where the total load is divided equally between the heat sources. However, it is still higher than that of the base cascade system heating load output.

The deviation of the hybrid system from the base system is defined as:

$$
\eta_{z}=\frac{z_{\text {Hybrid }}-z_{\text {Base }}}{z_{\text {Base }}}
$$

In this expression, the variable $(z)$ could be any of the heat load output $(\dot{Q})$, the power consumption by the heat pump $(\dot{W})$ or the coefficient of performance $(C O P)$ of the Cascade system. The base system represents the corresponding variable for the Cascade heat pump when it uses the sea water as a heat source only with (2.1) kW heat extraction. Figure (5) shows the deviation variation with intermediate temperature and ground heat source contribution. It is obvious that the hybrid system exhibited higher heat load deviation $\left(\boldsymbol{\eta}_{\dot{Q}}\right)$ at $(\alpha)$ close to $(15 \%)$. However, the deviation is only $(1.8 \%)$ as a maximum value, the increase is almost insignificant. 


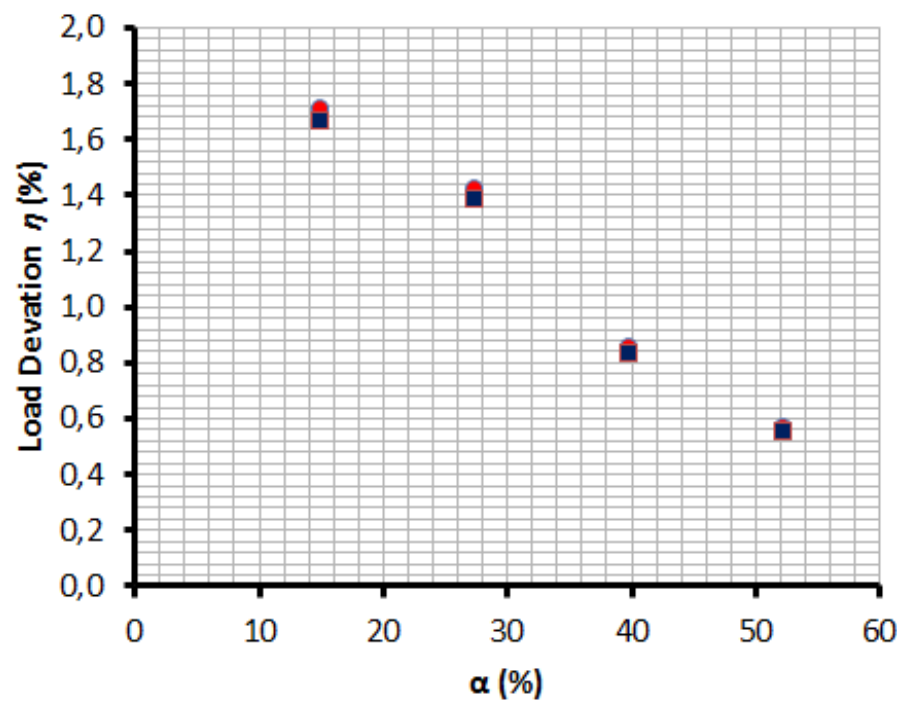

-R410A/R134a System @ Te_R134a=30 C

- R410A/R134a System @ Te_R134a=26C

Figure 5: Hybrid system load deviation $(\eta)$ when compared to the base load at different intermediate temperature for R410A/R134a system

\section{(ii) R717/R134a System}

The general trend of the load variation with $(\alpha)$ showed a similar behavior as that of R410A/R134a system with the intermediate temperature of the cascade heat exchanger. A higher heat output with a lower intermediate temperature at the cascade heat exchanger was experienced, figure (6). A higher value for the load output of the hybrid system at $(\alpha)$ near $(15$ $\%)$ of the total load input to the system as illustrated in figure (6).

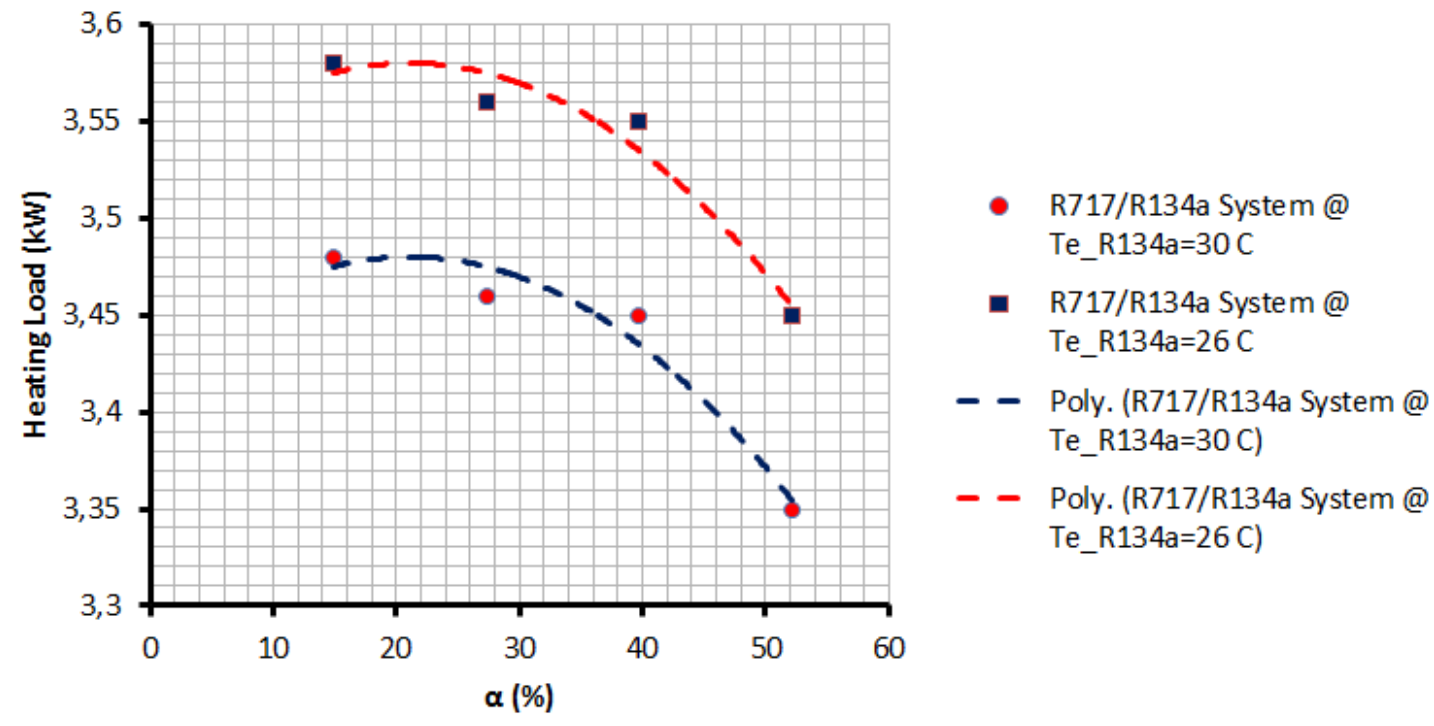

Figure 6: Heat pump heating load variation comparison at different intermediate temperature with $(\alpha)$ percentage for R717/R134a system 
The hybrid system exhibited a greater deviation from that of the R410A/R134a system to reach (-4 \%) at the condition when both heat sources are equally sharing the total input load, $(\alpha)$ is $(50 \%)$ as shown in figure (7). The hybrid system showed a lower heating load output by $(-4 \%)$ when compared to the base cascade system with sea water only as a heat source for the total input of (2.1) $\mathrm{kW}$ for the higher intermediate temperature.

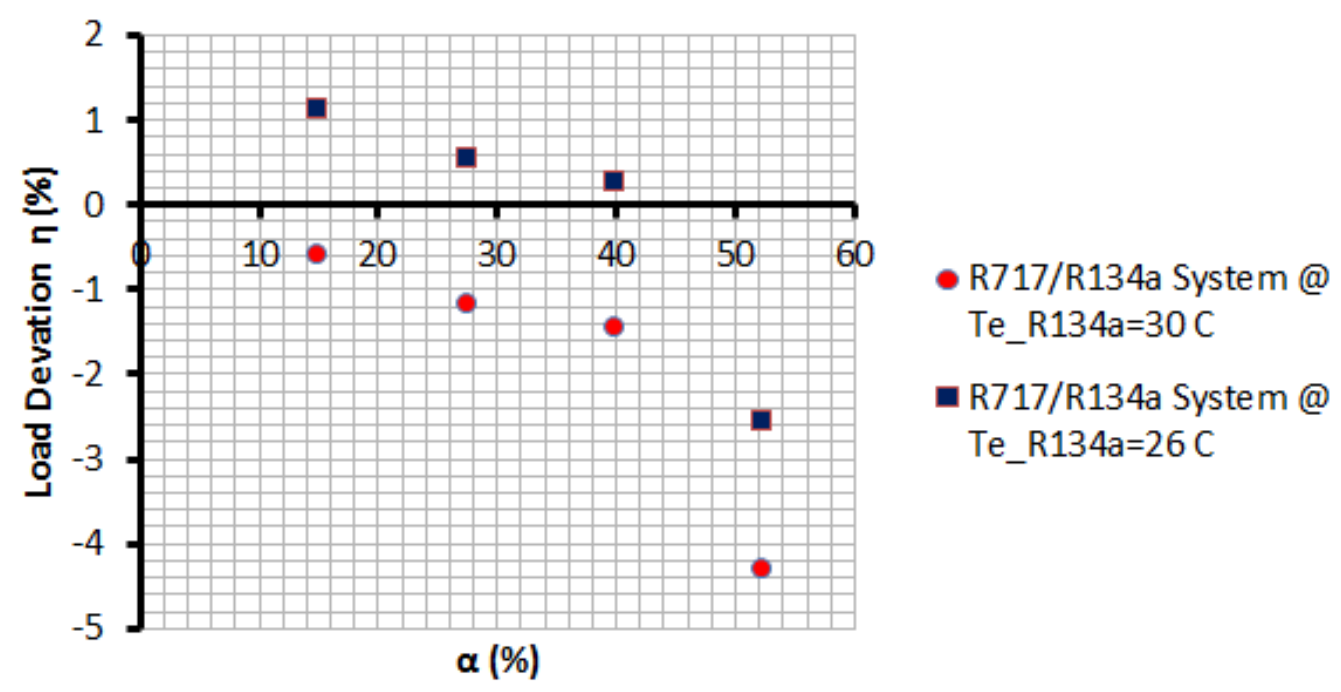

Figure 7: Hybrid system load deviation $(\eta)$ when compared to the base load at different intermediate temperature for R717/R134a system

At the same ground heat source contribution of $(50 \%)$ for R410A/R134a system, the deviation was a negligible value, which corresponds only $(0.6 \%)$. At the lower intermediate temperature, the hybrid system exhibited a higher heating load than that of the base one for $(\alpha)$ between (15 and 40) \%, but it is still within insignificant value of (1\%). Figure (7) reflects the fact that increasing the ground heat source contribution reduces the total heating load output of the heat pump. Hence, the application with $(\alpha)$ between $(15 \%)$ and $(40 \%)$ shows a favorite range for the R717/R134a system with $( \pm 1 \%)$ load deviation at both intermediate temperatures of the cascade heat exchanger.

\subsection{Compressors Power Consumption}

The power consumption of the Cascade systems for both of the refrigerant pairs are calculated with the aid of the basic thermodynamic relation described above. The isentropic efficiency of the three compressors was set at fixed value of $(70 \%)$. Figure (8) describes the variation of power consumption for R717/R134a system with $(\alpha)$ for different intermediate temperatures. 


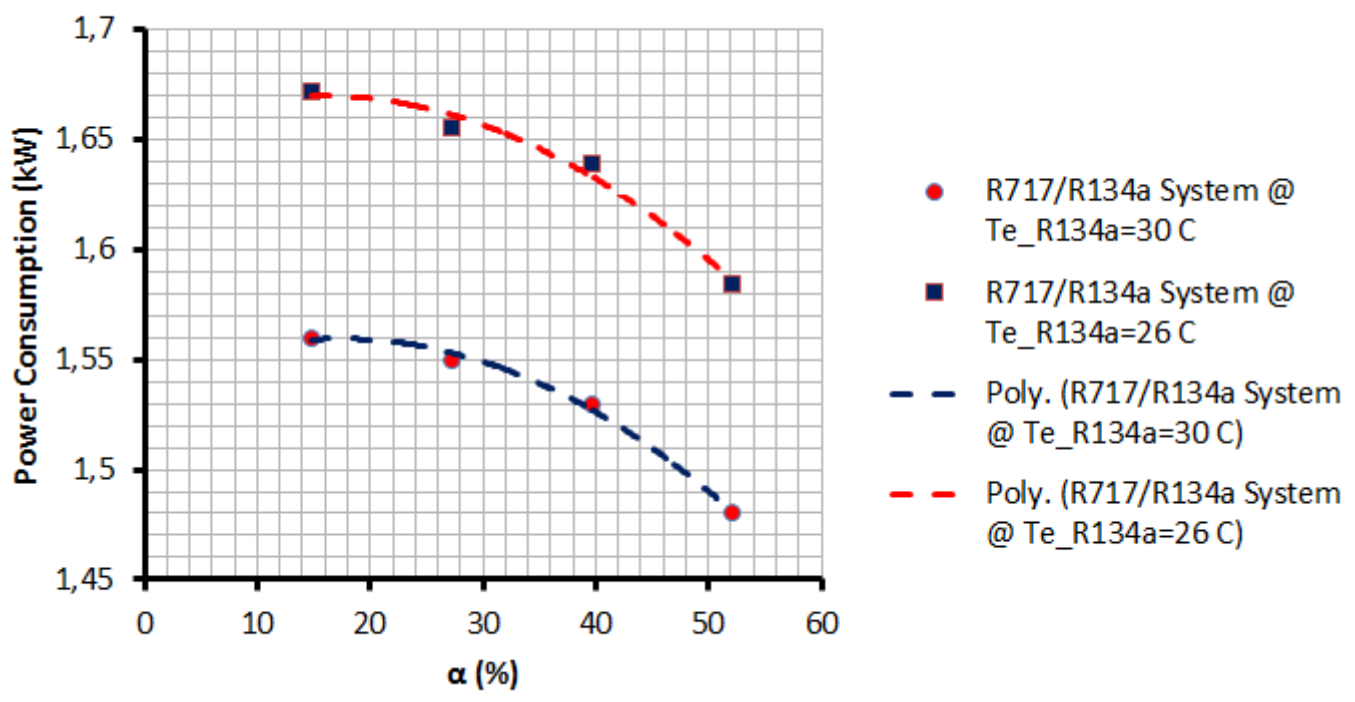

Figure 8: Heat pump power consumption comparison at different intermediate temperature with $(\alpha)$ parameter for R717/R134a system

The power consumption by compressors showed a higher value at lower intermediate temperature $(33){ }^{\circ} \mathrm{C}$. This behavior is similar to that of R410A/R134a system as well but with different magnitudes. The higher $(\alpha)$ exhibited the lower power consumption regardless of the intermediate temperature. It showed minimum and maximum power consumption at $(\alpha)$ of $(50$ $\%)$ and (15\%) respectively.

The contribution of each compressor to the total power consumption with $(\alpha)$ variation for R717/R134a system is compared in figure (9). The (LT) compressor contribution exhibited a declination with increasing ( $\alpha$ ); on the contrary the (IMT) compressor shows an increasing trend. This behavior is regardless of the (HT) operating conditions which showed insignificant variation with $(\alpha)$. This behavior is obviously due to the increase percentage of the load for the ground heat source and reducing the load contribution of the sea water source. The same trend has been noticed for R410A/R134a system as well

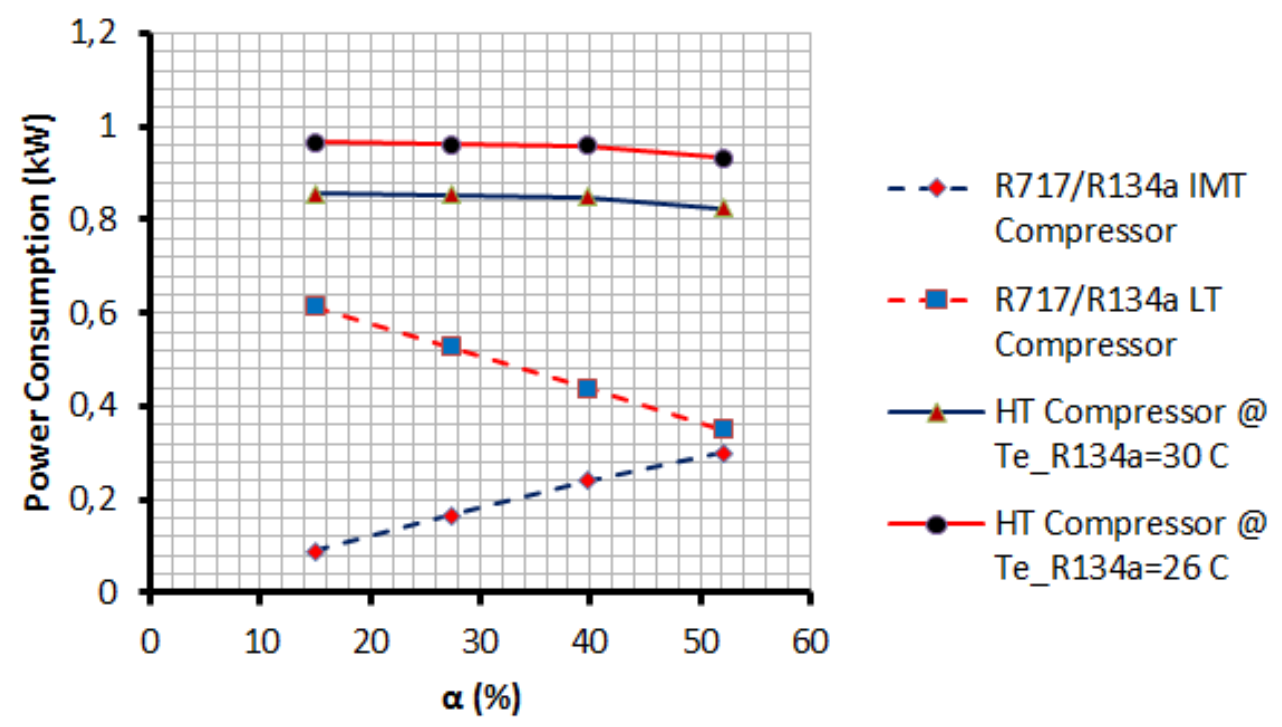

Figure 9: A comparison for compressors contributions to the compound Cascade system power consumption. 
A comparison of the power consumption for both of refrigerant pairs is presented in figure (10) for R134a evaporation temperature of $(30){ }^{\circ} \mathrm{C}$. It is obvious that the R410A/R134a system consumes more power than that of R717/R134a for the whole range of the investigated $(\alpha)$. It is ranged between $(6 \%)$ and $(8 \%)$ higher than those of R717/R134a system at $(\alpha)$ values of $(15 \%)$ and $(50 \%)$ respectively. Both systems revealed a decrease in the power consumption with the increase of $(\alpha)$.

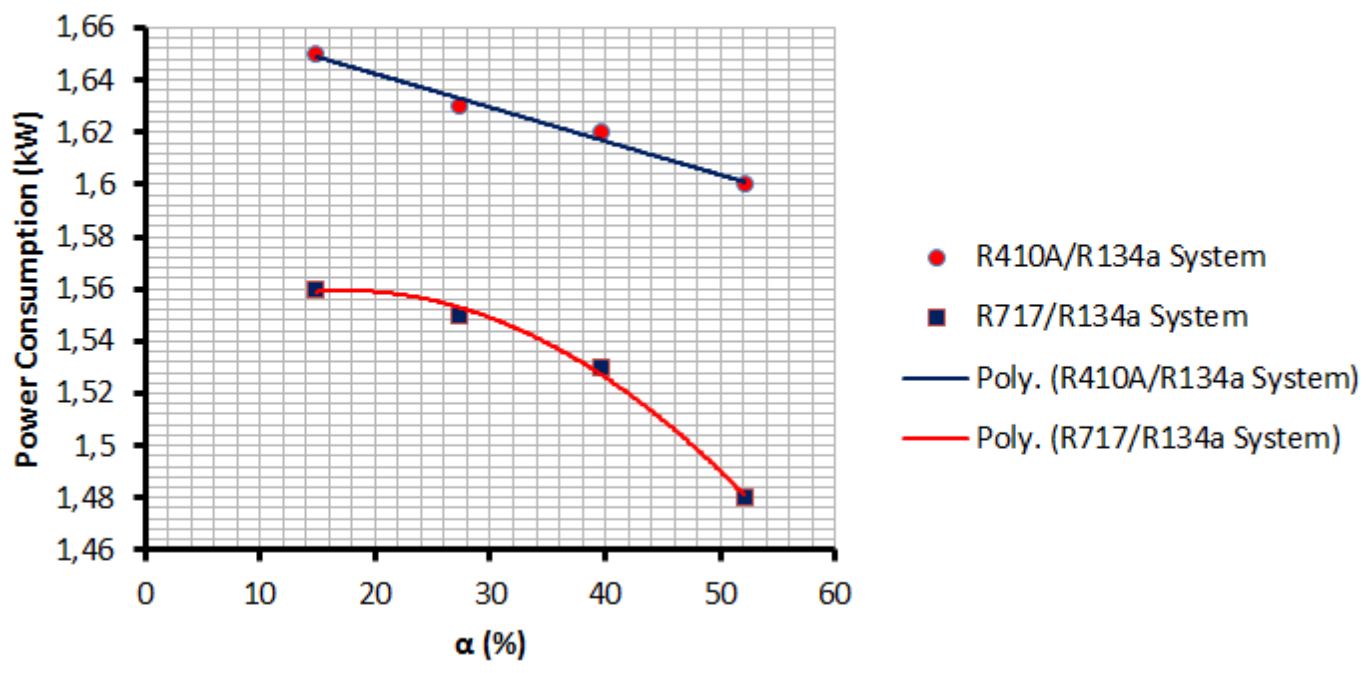

Figure 10: Heat pump power consumption comparison at $\mathrm{Te} \_\mathrm{R} 134 \mathrm{a}=30{ }^{\circ} \mathrm{C}$ and $\mathrm{HT}$ condensation temperature of

$$
\text { Tc_R134a }=7 \overline{5}^{\circ} \mathrm{C}
$$

Comparing the estimated power consumption to the base Cascade system values for R410A/R134a system at different intermediate temperatures is presented in figure (11). The percentage of power consumption departure from the base value is in favor for the range of $(\alpha)$ between $(30 \%)$ and $(50 \%)$ for this system. It showed that the power consumed by the hybrid system lower than that of the base system by about $(2.5 \%)$ at the maximum investigated $(\alpha)$.

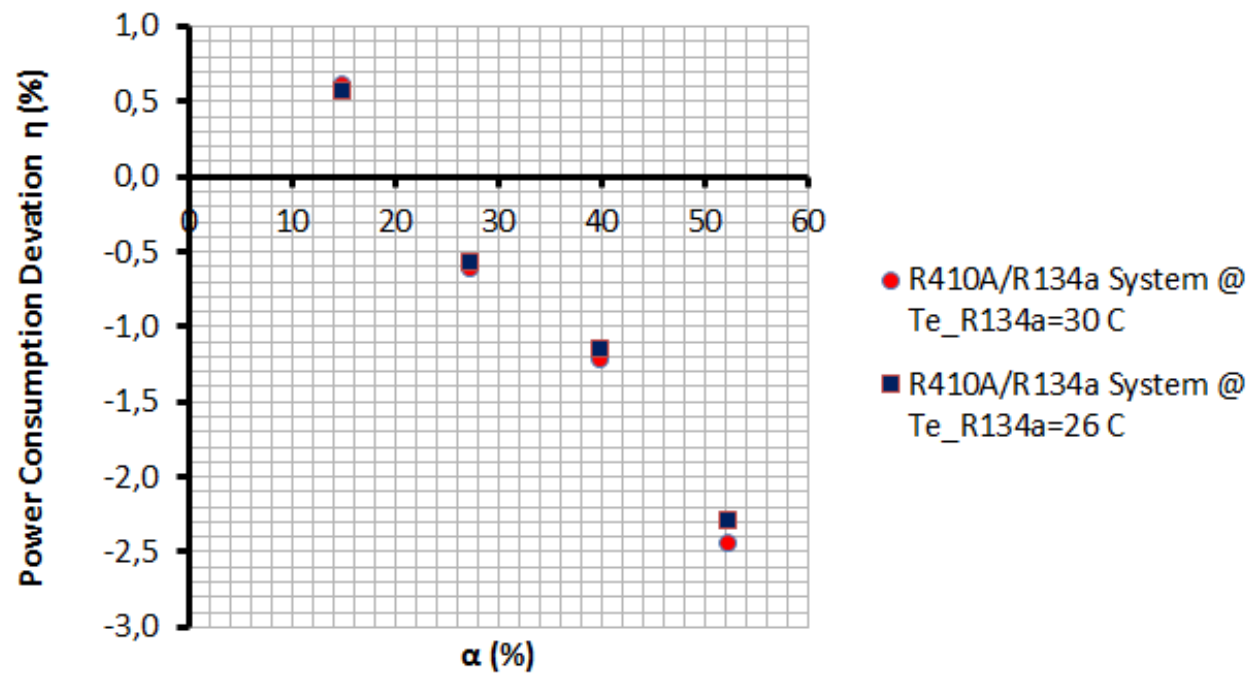

Figure 11: Hybrid system power consumption deviation $(\eta)$ when compared to the base value at different intermediate temperature for R410A/R134a system 


\subsection{System Heating COP}

The coefficient of performance of both Cascade refrigerant pair systems are compared in figure (12) for condensing temperature of $(30){ }^{\circ} \mathrm{C}$ at the HT cycle.

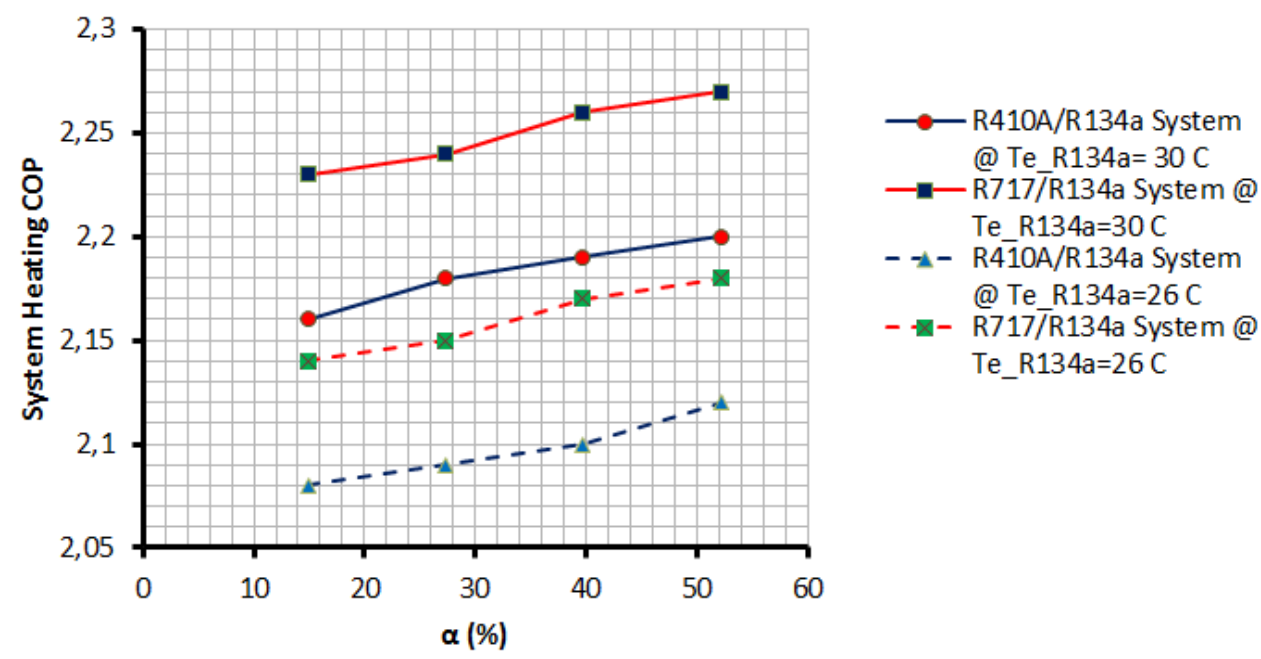

Figure 12: Heat pump heating $C O P$ comparison at $\mathrm{Te} \_\mathrm{R} 134 \mathrm{a}=30{ }^{\circ} \mathrm{C}$ and $26{ }^{\circ} \mathrm{C}$ with $(\mathrm{HT})$ condensing temperature Tc_R134a $=75^{\circ} \mathrm{C}$

The differences between heating $(C O P)$ of both systems are insignificant but they still show a sort of discrepancy with intermediate temperature, $(\alpha)$ values and refrigerant pairs. The higher $(C O P)$ was revealed for R717/R134a system than those of the R410A/R134a one for both of the intermediate temperatures at the whole investigated range of $(\alpha)$. R717/R134a system exhibited (COP) increase of about ( $3 \%$ ) higher than that of R410A/R134a system for both of the tested intermediate temperatures. In addition, the higher intermediate temperature (35) ${ }^{\circ} \mathrm{C}$ showed a higher heating $(C O P)$ than that of (33) ${ }^{\circ} \mathrm{C}$ for both of refrigerant Cascade systems. At $(35)^{\circ} \mathrm{C}, \mathrm{R} 717 / \mathrm{R} 134 \mathrm{a}$ system revealed a higher heating $(C O P)$ than that obtained at (33) ${ }^{\circ} \mathrm{C}$ by $(4 \%)$. The corresponding value for R410A/R134a system was about (3.8\%). The behavior of the estimated performance showed that the heating $(C O P)$ increases as $(\alpha)$ increases and approaching a maximum at the (50\%) input load contribution of each heat sources.

The $(C O P)$ of the system is an outcome of the thermal achievement of the heat pump. A comparison of both systems at the same intermediate temperature showed that R717/R134a exhibited a lower heating output load and power consumptions. Hence, a higher heating $(C O P)$ may be expected for this system. Figure (13) illustrate a comparison for the heating output load of the heat pump for the same operating conditions at intermediate temperature of $(35){ }^{\circ} \mathrm{C}$. 


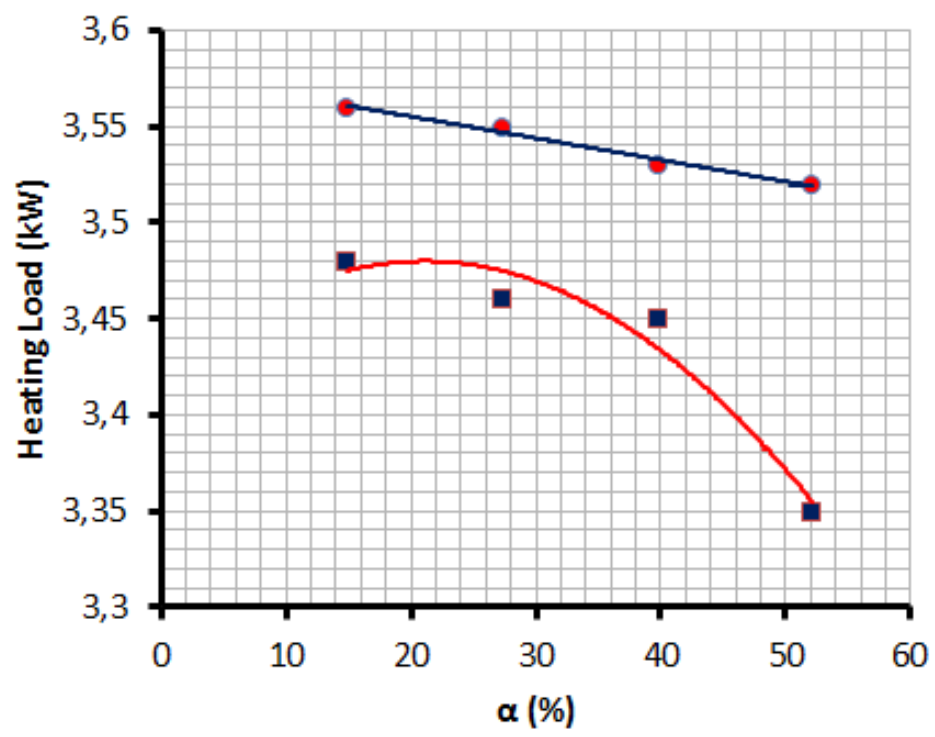

- R410A/R134a System

- R717/R134a System

— Poly. (R410A/R134a System)

— Poly. (R717/R134a System)

Figure 13: Heat pump heating load comparison at Te_R134a $=30{ }^{\circ} \mathrm{C}$ and $\mathrm{Tc} \_\mathrm{R} 134 \mathrm{a}=75^{\circ} \mathrm{C}$

It is obvious that the heating load output for R717/R134a system is lower than that of R410A/R134a one for the whole of the investigated range of $(\alpha)$. It is ranged between $(2 \%)$ at low value of $(\alpha)$ to $(5 \%)$ at the highest $(\alpha)$ of $(50 \%)$.

The specific power consumption of compressors is defined as the ratio of power consumed to the heating load output of (3.5) $\mathrm{kW}$ expressed as:

$$
W=\frac{\dot{W}_{\text {total,comp }}}{3.5}
$$

The test systems showed a similar behavior and trend variation with $(\alpha)$ and intermediate temperatures. Figure (14) illustrates a comparison of the variation of specific power consumption with $(\alpha)$ at different intermediate temperatures for R717/R134a system. The higher values of $(W)$ are revealed at the lower intermediate temperature of (33) ${ }^{\circ} \mathrm{C}$, it also showed the highest values at the lowest value of $(\alpha)$. Figure (15) shows the deviation percent of the specific power consumption of R410A/R134a and R717/R134a Cascade systems from the base value calculated at (3.5) kW output heating load. The values of (W) showed a decrease by a value upto (3) \% lower than that of the base system where sea water heat source was implemented alone. 


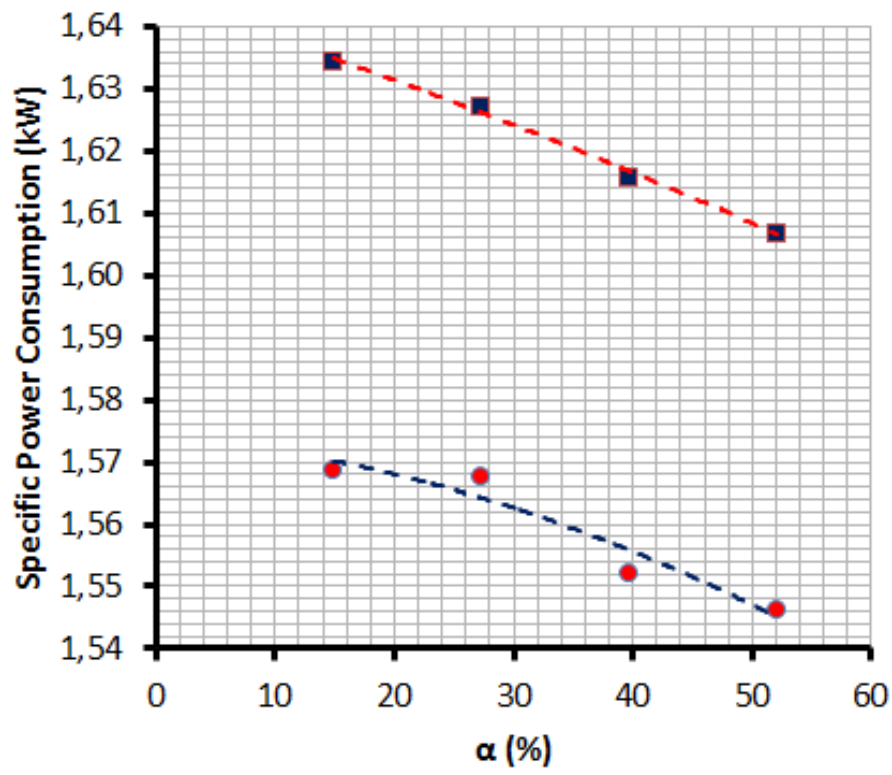

- R717/R134a System @ Te_R134a $=30 \mathrm{C}$

- R717/R134a System @ Te_R134a $=26 \mathrm{C}$

- - - Poly. (R717/R134a System @ Te_R134a=30 C)

- - - Poly. (R717/R134a System @ Te_R134a=26C)

Figure 14: A comparison of the specific power consumption at different intermediate temperatures for R717/R134a system

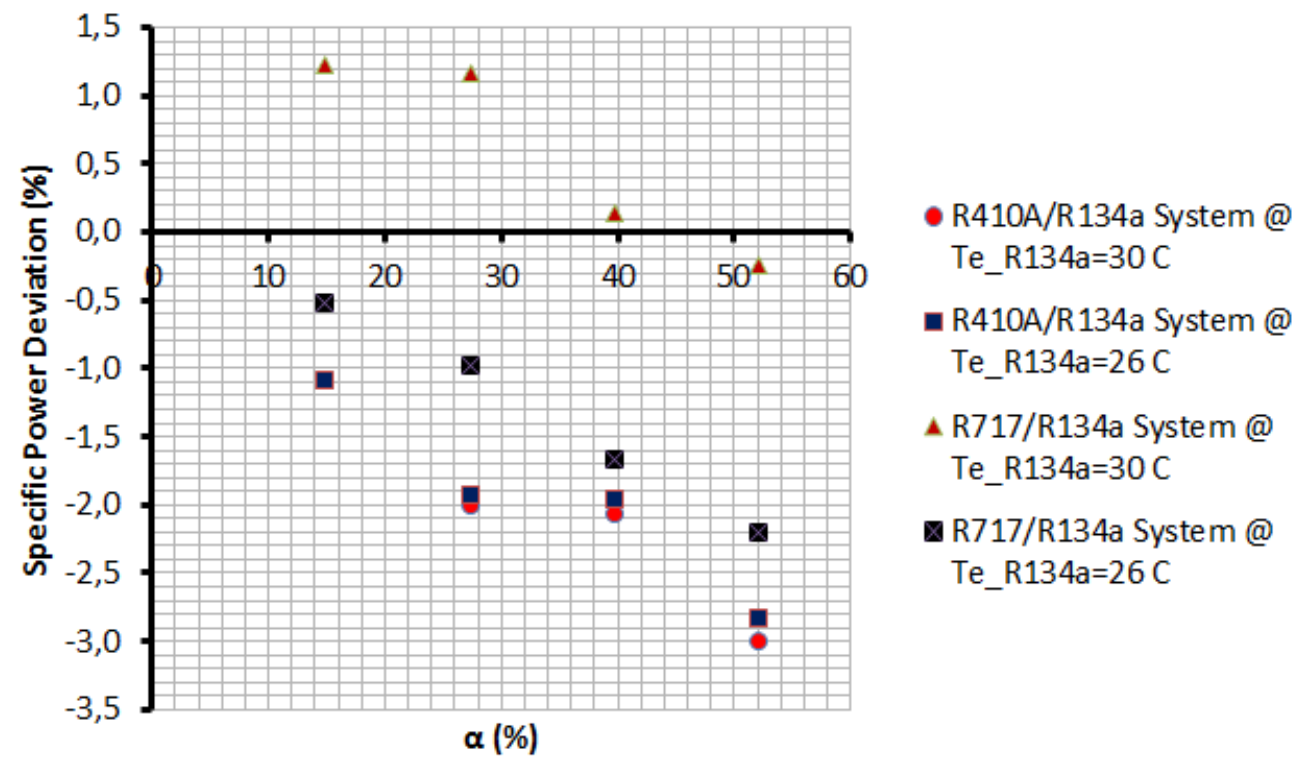

Figure 15: The variation of specific power consumption deviation from the base reference for the proposed compound Cascade system.

\section{CLOSURE STATEMENT}

It is worth mentioning that the above assessment of the base and proposed coupling of multi heat source systems were based on the maximum possible power to be consumed by the Cascade unit. Increasing the isentropic efficiency of the compressors to $(90 \%)$ revealed a significant reduction in the power consumed by the Cascade system by more than (24 \%) and an increase of the $(C O P)$ by about $(20 \%)$. For R717/R134a system at $(30){ }^{\circ} \mathrm{C}$ evaporation temperature of R134a in the 
cascade heat exchanger and keeping the other operating conditions fixed with the same input load of (2.1) $\mathrm{kW}$ showed that the $(C O P)$ was increased from (2.26) to (2.7) to correspond (20\%) higher. The corresponding figures for (26) ${ }^{\circ} \mathrm{C} \mathrm{R} 134 \mathrm{a}$ evaporation temperature were (2.1) and (2.6) respectively with increase of $(20 \%)$ for the $(C O P)$.

Implementing $R 717$ alone in the compound Cascade unit with the above operating conditions revealed an improvement in the (COP) of the system to reach (2.8). It reduced the power consumption further by more than (7\%) to improve (COP) by (24\%) under the same operating conditions and input heating load.

\section{CONCLUSIONS AND RECOMMENDATIONS}

The present study revealed the following findings:

1- Two heat sources were analyzed with simple thermodynamic concept for compression refrigeration cascade system.

2- R717/R134a system exhibited better thermal performance with lower power consumption when compared to those of R410A/R134a one.

3- The specific power consumption of the suggested system showed a decrease in the range of (1 to 3$) \%$ when compared to that of the base system of sea water heat source alone.

4- At (35) ${ }^{\circ} \mathrm{C}$ intermediate temperature, both of the investigated systems revealed a higher heating (COP) than that obtained at $(33){ }^{\circ} \mathrm{C}$ by about $(4 \%)$.

5- The results showed that increasing the isentropic efficiency of compressors to (90\%) improved the heating $(C O P)$ by $(20 \%)$ and minimized the power consumption by $(24 \%)$.

6- The proposed compound Cascade system provides good flexibility to manipulate the contribution percentage of each heat source according to its availability.

7- Installing a superheater heat exchanger after the (LT) evaporator on the suction line of compressor with ground heat source can improve the overall efficiency of the system.

8- Installing an economizer where subcooling of the condensate out of the cascade heat exchanger provides good superheating at the (LT) cycle and improves the thermal performance of the compound Cascade system.

\section{ACKNOWLEDGEMENT}

The author would like to express his sincere thanks to Mechatronic Department in the University of Southern Denmark (SDU) for providing the facilities to accomplish this work.

\section{NOMENCLATURE}

$\begin{array}{ll}\text { Parameter } & \text { Definition } \\ C O P & \text { Coefficient of performance (Dimensionless) } \\ h & \text { Fluid enthalpy, }(\mathrm{kJ} / \mathrm{kg}) \\ \dot{m} & \text { Fluid mass flow rate }(\mathrm{kg} / \mathrm{s}) \\ \dot{Q} & \text { Heating load }(\mathrm{kW}) \\ \mathrm{T} & \text { Temperature }\left({ }^{\circ} \mathrm{C}\right) \\ \dot{W} & \text { Compressor power consumption }(\mathrm{kW}) \\ \dot{W} & \text { Compressor specific power consumption }(\mathrm{kW} / \mathrm{kW}), \\ & \text { defined by eq. }(14) \\ \mathrm{z} & \text { Variable defined in eq. }(13)\end{array}$

\section{Subscripts}

Base $\quad$ Base or reference value

cascade Cascade heat exchanger

comp Compressor

cond Condenser

evap Evaporator

$G-S \quad$ Ground heat source

$H T \quad$ High temperature side

IMT Intermediate temperature

LT Low temperature side 


$\begin{array}{ll}\text { LTC } & \text { Low temperature cycle } \\ m & \text { Mean value of mixture } \\ S-W & \text { Sea water heat source } \\ \text { total } & \text { Total value }\end{array}$

\section{Greek Letters}

$\alpha \quad$ Ground heat source contribution with respect to the total

input load defined in eq. (12), (\%)

$\eta \quad$ Parameter deviation percent defined in eq. (13)

\section{REFERENCES}

[1] Lee, T. S., Liu, C. H. and Chen, T. W., "Thermodynamic analysis of optimal condensing temperature of cascade condenser in CO2/NH3 cascade refrigeration systems", Int. J. Ref., 29, pp. 1100-1108, (2006).

[2] Bhattacharyya, S., Mukhopadhyay, S., Kumar, A., Khurana, R. K. and Sarkar, J., "Optimization of a CO2-C3H8 cascade system for refrigeration and heating", Int. J. Ref., 28, (2005).

[3] Bingming, W., Huagen, W., Jianfeng, L. and Ziwen, X., "Experimental investigation on the performance of NH3/CO2 cascade refrigeration system with twin-screw compressor", Int. J. Refrigeration 32, pp. 1358-1365, (2009).

[4] Dopazo, J.A. and Fernández-Seara, J., "Experimental evaluation of a cascade refrigeration system prototype with $\mathrm{CO} 2$ and NH3 for freezing process applications", Int. J. Refrigeration 34, pp. 257-267, (2011).

[5] Kim, D. H., Park, H. S. and Kim, M. S., "Characteristics of R134a/R410A Cascade Heat Pump and Optimization", International Refrigeration and Air Conditioning Conference at Purdue, Paper n. 2425, pp1-7, (2012)

[6] Kim, J., Lee, J. Choi, H, Lee S., Oh, S. and Park, W., "Experimental study of R134a/R410A cascade cycle for variable refrigerant flow heat pump systems", Journal of Mechanical Science and Technology 29 (12), pp. 5447-5458, (2015), DOI 10.1007/s12206-015-1146-2

[7] Minglu, Q., Yanan, F., Jianbo, C., Tianrui, L., Zhao, L., and He, L., "Experimental study of a control strategy for a cascade air source heat pump water heater", Applied Thermal Engineering, (2016), DOI: http://dx.doi.org/10.1016/j.applthermaleng.2016.08.176

[8] "Energy Efficiency and Renewable Energy", Guide to Geothermal Heat Pumps, U.S. Department of Energy, DOE/EE0385, February (2011).

[9] Ozgener, O.; Hepbasli, A. A, "Review on the energy and exergy analysis of solar assisted heat pump systems", Renew. Sustain. Energy Rev., 11, 482-496, (2007).

[10] Yrjölä, J and Laaksonen, E., "Domestic Hot Water Production with Ground Source Heat Pump in Apartment Buildings", Energies, 8, 8447-8466, (2015) doi:10.3390/en8088447.

[11] Uhlmann, M., Bertsch, S., and Heldstab, A., (2014), "Heat Pump with Two Heat Sources on Different Temperature Levels", International Refrigeration and Air Conditioning Conference. Paper no. 1372. http://docs.lib.purdue.edu/iracc/1372.

[12] Lund, H., Werner, S., Wiltshire, R., Svendsen, S., Thorsen, J. E., Hvelplund, F. and Mathiesen, B. V., 2014," 4th Generation District Heating (4GDH), Integrating smart thermal grids into future sustainable energy systems", Energy 68, pp. 1-11, (2014).

[13] Domestic Ground Source Heat Pumps, "Design and installation of closed-loop systems", report pp. 10, (2007 edition). 